\title{
PENGEMBANGAN LKS IPA BERBASIS KEARIFAN LOKAL KOPI PADA POKOK BAHASAN USAHA DAN ENERGI DI SMP
}

\author{
${ }^{1)}$ Rosita Sari, 1) Alex Harijanto, ${ }^{1)}$ Sri Wahyuni \\ ${ }^{1)}$ Program Studi pendidikan Fisika FKIP Universitas Jember \\ rositasirasio@ymail.com
}

\begin{abstract}
The purpose research and development of students worksheets science based on local wisdom of coffee on the subject effort and energy were described validity of product, described critical thinking skill of students and described students response. This worksheets arranged with indicators of critical thinking were interpretation, analysis, inference, evaluation, explanation, and self regulation. The design of this research and development by Sugiyono that was (1) potential and problem, (2) data collection, (3) the product design, (4) validation design, (5) revision design, (6) testing products, and (7) revision products. The techniques of data collection were validity, test, questionnaire, and documentation. The result showed that (1) the students worksheets science based on local wisdom of coffee was very valid and value of validation $86,43 \%$ it can be used without revision; (2) the students worksheets science based on local wisdom of coffee was effective to increase critical thinking skill of students and value indicators of critical thinking skill 72,99\% with good predicate, and $N$-gain value 0,47 with medium category; and (3) the students worksheets science based on local wisdom of coffee was very practically to students and the value of students response 85,98\% with very good category.
\end{abstract}

Key word: local wisdom, validity, critical thinking, students response

\section{PENDAHULUAN}

Pembelajaran Ilmu Pengetahuan Alam (IPA) secara terpadu dalam praktiknya masih menghadapi kendala, salah satu kendalanya ialah kurangnya sumber belajar untuk siswa. Hasil wawancara dengan salah satu guru IPA di SMP Argopuro 2 Suci memberikan informasi tentang kendala pembelajaran IPA ialah kurangnya sumber belajar yang menyebabkan pembelajaran terpaku pada satu buku. Proses pembelajaran IPA di sekolah menggunakan satu bahan ajar yang biasa disebut LKS (Lembar Kerja Siswa). LKS yang digunakan menguraikan ringkasan materi dan latihan soal. LKS tersebut telah sesuai dengan kurikulum dan kebutuhan siswa, hanya saja aplikasi konsep yang disajikan masih secara umum dan belum menyajikan permasalahan yang berkaitan dengan kearifan lokal. Selain itu, guru mengaku sangat jarang mengaitkan konsep materi IPA dengan kearifan lokal yang ada di sekitar lingkungan sekolah. Sehingga siswa belum pernah diajarkan pembelajaran yang berbasis kearifan lokal.

Kearifan lokal merupakan tradisi yang berkembang di masyarakat untuk mengelola sumber daya yang ada agar tetap terjaga kelestariannya. Kota Jember dikenal sebagai kota agraris yang banyak memproduksi komoditi kopi. Sehingga sudah selayaknya kearifan lokal kopi diinternalisasikan ke dalam pembelajaran di sekolah, agar siswa lebih mengenal kearifan lokal kopi di daerahnya. Karena dari hasil penyebaran angket $73,33 \%$ siswa menyatakan belum tau kearifan lokal yang ada di daerahnya. 
Salah satu inovasi yang bisa dilakukan untuk mengatasi permasalahan di atas ialah mengembangkan bahan ajar berupa Lembar Kerja Siswa (LKS) berbasis kearifan lokal. LKS dapat membangkitkan minat siswa jika LKS disusun secara rapi, sistematis, mudah dipahami sehingga mudah menarik perhatian siswa, serta dapat menumbuhkan kepercayaan pada diri siswa dan meningkatkan motivasi belajar dan rasa ingin tahu (Isnaningsih, 2013).

Penggunaan LKS berbasis kearifan lokal dalam pembelajaran IPA diyakini dapat menjadi salah satu strategi untuk memudahkan siswa memahami konsep IPA, sehingga kemampuan berpikirnya lebih berkembang. Strategi tersebut dapat memberikan nurturant effect pengembangan keterampilan seperti berpikir logis kritis (Hariri, dkk, 2016). Pembelajaran berbasis sains budaya lokal sangat penting dilakukan untuk memberikan wawasan pembelajaran secara kontekstual dalam meningkatkan keterampilan berpikir kritis, hal ini karena mengaitkan budaya lokal dengan pengetahuan sains siswa (Qolbi, dkk, 2016).

Kemampuan berpikir kritis yaitu kemampuan memprediksi dari keterbatan informasi, kemampuan untuk menemukan masalah, merumuskan hipotesis, menguji hipotesis dan kemampuan untuk melihat informasi dari berbagai pandangan (Martawijaya, 2015). Indikator kemampuan berpikir kritis dalam model Facione ada 6 diantaranya yaitu: 1) interpretation; 2) analysis; 3) testing; 4) interference; 5) explanation; dan 6) self regulation (pengaturan diri) (Atabaki, dkk, 2015).

Penelitian sebelumnya tentang pembelajaran berbasis kearifan lokal dilakukan oleh Wahyuni (2015), menyatakan bahwa perangkat pembelajaran IPA berbasis kearifan lokal yang dikembangkan dalam katagori valid sehingga cukup efektif dalam meningkatkan kemampuan berpikir kritis siswa. Selain itu Qolbi, dkk (2016) menunjukkan peningkatan keterampilan berpikir kritis yang signifikan antara kelas yang menggunakan pembelajaran berbasis sains budaya lokal dengan kelas yang menggunakan metode konvensional.

Berdasarkan permasalahan kurangnya sumber belajar IPA dan inovasi pembelajaran yang ditawarkan, maka tujuan dari penelitian dan pengembangan ini adalah mendeskripsikan validitas LKS IPA berbasis kearifan lokal kopi, mendeskripsi-kan kemampuan berpikir kritis siswa menggunakan LKS IPA berbasis kearifan lokal kopi, dan mendeskripsikan respon siswa terhadap LKS IPA berbasis kearifan lokal kopi.

\section{METODE}

Jenis penelitian ini adalah penelitian pengembangan yang dirancang untuk memperoleh produk. Produk yang dimaksud berupa LKS IPA berbasis kearifan lokal kopi pada pokok bahasan Usaha dan Energi di SMP.

Penelitian dilaksanakan di SMP Argopuro 2 Suci pada waktu semester genap tahun ajaran 2016/2017. Subjek penelitian adalah 39 siswa kelas VIII B.

Penelitian dan pengembangan ini mengacu pada rancangan model Sugiyono. Model pengembangan Sugiyono terdiri dari 10 tahap yaitu (1) potensi dan masalah, (2) pengumpulan data, (3) desain produk, (4) validasi desain, (5) revisi desain, (6) ujicoba produk, (7) revisi produk, (8) ujicoba pemakaian, (9) revisi produk, dan (10) produksi massal. Namun, penelitian dan pengembangan yang dilakukan hanya sampai pada tahap ke-7. Hal ini diperbolehkan sebagaimana Borg \& Gall (dalam Emzir, 2013: 271) menyatakan bahwa dimungkinkan untuk membatasi penelitian dalam skala kecil, termasuk membatasi langkah penelitian. 
Instrumen pengumpulan data dalam penelitian ini menggunakan instrumen lembar validasi, lembar pre tes dan post test, serta angket respon siswa. Teknik perolehan data yang dilakukan ialah teknik validasi, tes, angket, dan dokumentasi.

Teknik analisis data validasi menggunakan teknik persentase. Rumus yang digunakan adalah.

Dengan:

$$
V_{-a h}=\frac{T S e}{T S h} \times 100 \%
$$

$V_{-a h}=$ validasi ahli

TSe =total skor empiris yang diperoleh

TSh $=$ total skor maksimal

$100 \%=$ konstanta

Nilai validasi yang diperoleh selanjutnya diterjemahkan ke dalam kriteria validitas seperti pada Tabel 1 berikut.

Tabel 1. Kriteria validasi

\begin{tabular}{ccl}
\hline No & $\begin{array}{c}\text { Kriteria } \\
\text { Validitas }\end{array}$ & \multicolumn{1}{c}{ Tingkat Validitas } \\
\hline 1 & $85,01 \%-100 \%$ & $\begin{array}{l}\text { Sangat valid, dapat } \\
\text { digunakan tanpa } \\
\text { revisi }\end{array}$ \\
\hline 2 & $70,01 \%-85,00 \%$ & $\begin{array}{l}\text { Cukup valid, dapat } \\
\text { digunakan namun } \\
\text { perlu direvisi kecil }\end{array}$ \\
\hline 3 & $50,01 \%-70,00 \%$ & $\begin{array}{l}\text { Kurang valid, dapat } \\
\text { digunakan namun } \\
\text { perlu revisi besar }\end{array}$ \\
\hline 4 & $01,00 \%-50,00 \%$ & $\begin{array}{l}\text { Tidak valid, tidak } \\
\text { dapat dipergunakan }\end{array}$ \\
\hline
\end{tabular}

Akbar (2013: 41)

Teknik analisis data kemampuan berpikir kritis siswa setiap indikator adalah.

Keterangan:

$$
\text { persentase }(\%)=\frac{n m}{N} \times 100 \%
$$

$n m$ : jumlah item yang di cek dari tiap aspek daftar cek

$N$ : jumlah seluruh item dari setiap aspek daftar cek

Slameto (dalam Dewa, 2017)

Kriteria Kemampuan Berpikir Kritis (KBK) dapat dilihat pada Tabel 2 berikut.
Tabel 2. Kriteria KBK

\begin{tabular}{cc}
\hline Tingkat Penguasaan & Predikat \\
\hline $76-100 \%$ & Baik sekali \\
\hline $51-75 \%$ & Baik \\
\hline $27-50 \%$ & Cukup \\
\hline$\leq 26 \%$ & Kurang \\
\hline & Sochibin (2009.99)
\end{tabular}

Kemampuan berpikir kritis siswa sebelum dan sesudah menggunakan LKS dihitung melalui $N$-gain berdasarkan pre test dan post test dengan rumus sebagai berikut.

$N . g=\frac{\text { skor test akhir-skor test awal }}{\text { skor maks yg diperoleh-skor test awal }}$

Nilai $\mathrm{N}$-gain yang diperoleh,kemudian diinterpretasikan pada Tabel 3 berikut.

Tabel 3. Interpretasi Nilai $N$-gain

\begin{tabular}{ll}
\hline Nilai N-gain & Interpretasi \\
\hline $\mathrm{g} \geq 0,7$ & Tinggi \\
\hline $0,7>\mathrm{g} \geq 0,3$ & Sedang \\
\hline $\mathrm{g}<0,3$ & Rendah \\
\hline & Hake (dalam Ain, 2013:99)
\end{tabular}

Hasil dari $n$-gain score $(g)$ dikatakan sudah sesuai apabila nilai tersebut mencapai kriteria Cukup sampai Tinggi (Permatasari \& Ismono, 2017: 27).

Teknik analisis data respon siswa dihitung menggunakan rumus berikut.

percentage of agreement $=\frac{A}{B} \times 100 \%$

Keterangan:

$\mathrm{A}=$ total skor respon yang dicapai

$\mathrm{B}=$ total skor yang diharapkan

Trianto (dalam Sari, 2015:269)

Hasil analisis respon yang diperoleh diinterpretasikan pada Tabel 4 berikut:

Tabel 4. Interpretasi Skala Likert

\begin{tabular}{cc}
\hline Prosentase & Kriteria \\
\hline $0 \%-20 \%$ & Sangat kurang \\
\hline $21 \%-40 \%$ & Kurang \\
\hline $41 \%-60 \%$ & Cukup \\
\hline $61 \%-80 \%$ & Baik \\
\hline $81 \%-100 \%$ & Sangat baik \\
\hline LKS dikatakan & layak jika
\end{tabular}

menghasilkan persentase $\geq 61 \%$ pada kriteria baik atau sangat baik (Riduwan, 2015). 


\section{HASIL DAN PEMBAHASAN}

Tahap pertama adalah potensi dan masalah. Kota Jember memiliki kearifan lokal kopi yang sebaiknya dikembangkan dalam pembelajaran IPA. Hal ini juga sesuai peraturan Kemendikbud yaitu pembelajaran IPA terpadu ditujukan untuk pengenalan lingkungan biologi dan alam sekitarnya, serta pengenalan berbagai keunggulan wilayah nusantara. Masalah yang ditemukan diantaranya (1) kurangnya pemanfaatan kearifan lokal dalam pembelajaran IPA. (2) kurangnya sumber belajar IPA untuk siswa.

Tahap kedua adalah pengumpulan informasi. Pengumpulan informasi dilakukan melalui analisis kebutuhan terhadap produk yang akan dikembangkan. Analisis kebutuhan dilakukan melalui dua tahap yaitu studi pustaka dan studi lapangan.

Tahap ketiga adalah desain produk. Desain LKS disusun berdasarkan 6 indikator berpikir kritis, dengan urutan penyajian interpretasi, analisis, inferensi, evaluasi, eksplanasi, dan self regulation. Format LKS disusun dengan urutan antara lain: (1) cover LKS, (2) kata pengantar, (3) daftar isi, (4) petunjuk pengguna, (5) standar isi, (6) peta konsep, (7) pendahuluan, (8) isi LKS, (9) catatan, dan (10) daftar pustaka. Berikut ini contoh gambar desain cover LKS.

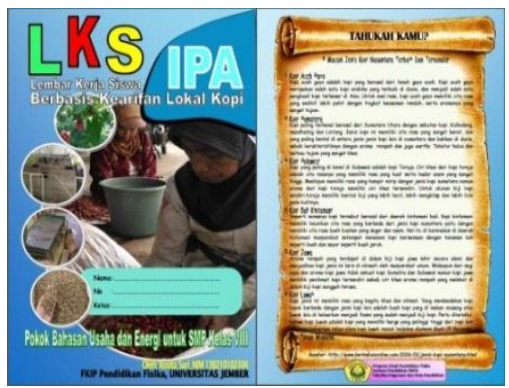

Gambar 1. Tampilan sampul LKS

Tahap keempat adalah validasi desain. Validasi desain melalui dua tahap validasi yaitu, pertama validasi ahli dan kedua validasi pengguna. Selanjutnya dari dua tahap validasi ini dilakukan perhitungan ratarata hasil uji validasi ahli dan validasi pengguna. Maka diperoleh hasil validasi pada Tabel 5 sebagai berikut.

Tabel 5. Validasi LKS

\begin{tabular}{|c|c|c|c|c|c|c|c|}
\hline \multirow{2}{*}{$\begin{array}{l}\text { Aspek yang } \\
\text { diamati }\end{array}$} & \multicolumn{2}{|c|}{$\mathbf{V}_{\text {ah }}$} & \multicolumn{2}{|c|}{$V_{\text {pg }}$} & \multirow{2}{*}{$\begin{array}{c}V_{\text {rt2 }} \\
\text { Aspek }\end{array}$} & \multirow[b]{2}{*}{ Validasi } & \multirow{2}{*}{$\begin{array}{c}\text { Tingkat } \\
\text { Validitas }\end{array}$} \\
\hline & $\begin{array}{l}\text { Vah_rt2 } \\
\text { Aspek }\end{array}$ & $\mathbf{V}_{\text {ah }}$ & $\begin{array}{l}V_{\text {pg_rt2 }} \\
\text { Aspek }\end{array}$ & $V_{p g}$ & & & \\
\hline Kelayakan Isi & $76,67 \%$ & \multirow{4}{*}{$78,29 \%$} & $90,67 \%$ & \multirow{4}{*}{$94,57 \%$} & $83,67 \%$ & \multirow{4}{*}{$86,43 \%$} & \multirow{4}{*}{$\begin{array}{c}\text { Sangat valid } \\
\text { atau dapat } \\
\text { digunakan } \\
\text { tanpa revisi. }\end{array}$} \\
\hline $\begin{array}{l}\text { Kelayakan } \\
\text { Penyajian }\end{array}$ & $80,00 \%$ & & $92,86 \%$ & & $86,43 \%$ & & \\
\hline Desain & $81,11 \%$ & & $100 \%$ & & $90,56 \%$ & & \\
\hline Bahasa & $75,00 \%$ & & $100 \%$ & & $87,50 \%$ & & \\
\hline
\end{tabular}

Berdasarkan pada Tabel 5, menunjukkan nilai rata-rata validitas LKS yang dikembangkan sebesar $86,43 \%$. Nilai validitas tersebut berada pada rentang $85,01 \%-100,00 \%$ dengan kriteria sangat valid, atau dapat digunakan tanpa revisi. Hal ini sesuai dengan hasil penelitian Lase,dkk
(2016) bahwa, persentase skor rata-rata aspek kelayakan isi LKS 88,10\%, aspek kelayakan penyajian LKS 91,35\%, dan aspek kelayakan desain LKS 97\%.

Tahap kelima adalah revisi desain. Revisi desain dilakukan berdasarkan komentar dari validator, diantaranya ialah 
memperbaiki tujuan pembelajaran LKS disesuaikan untuk meningkatkan berpikir kritis, serta menambahkan penerapan kearifan lokal kopi dalam materi pada LKS.

Tahap keenam adalah tahap ujicoba. Ujicoba dilaksanakan di kelas VIII B SMP Argopuro 2 Suci semester genap tahun ajaran 2017/2018. Subjek penelitian berjumlah 39 siswa. Penelitian selama 5 kali pertemuan. Data yang diperoleh adalah data kemampuan berpikir kritis dan respon siswa. Kemampuan berpikir kritis siswa dianalsis berdasarkan hasil penilaian LKS dan hasil tes siswa. Berikut ini grafik ketercapaian indikator kemampuan berpikir kritis siswa menggunakan LKS.

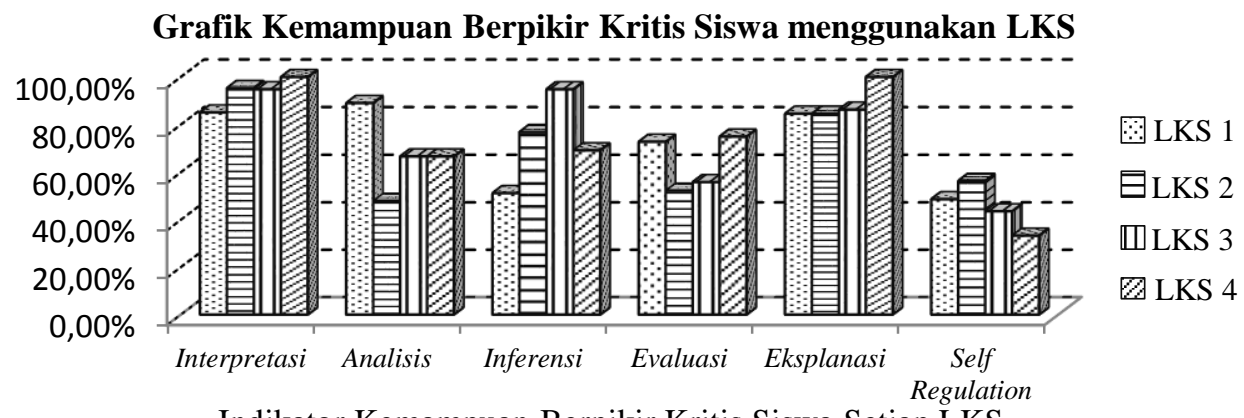

Indikator Kemampuan Berpikir Kritis Siswa Setiap LKS

Gambar 2. Grafik Indikator Kemampuan Berpikir Kritis Siswa

Gambar 2 di atas menunjukkan bahwa indikator intepretasi memperoleh nilai tertinggi dibanding indikator yang lainnya. Indikator analisis memperoleh pencapaian nilai tertinggi pada LKS 1. Indikator inferensi memperoleh pencapaian nilai tertinggi pada LKS 3. Indikator evaluasi memperoleh pencapaian nilai tertinggi pada LKS 4. Indikator eksplanasi memperoleh nilai terbaik pada LKS 4. Indikator self regulation memperoleh nilai terendah dibanding indikator yang lainnya. Grafik tersebut diperoleh berdasarkan hasil rekapitulasi penilaian LKS sebagai berikut.

Tabel 6. Hasil Rekapitulasi Nilai LKS Kemampuan Berpikir Kritis

\begin{tabular}{ccccccc}
\hline Indikator & \multicolumn{5}{c}{ Persentase Perolehan Skor } & \multirow{2}{*}{ Predikat } \\
\cline { 2 - 6 } Berpikir Kritis & LKS 1 & LKS 2 & LKS 3 & LKS 4 & Rata2 LKS & \\
\hline Interpretasi & $85,13 \%$ & $95,38 \%$ & $94,87 \%$ & $100 \%$ & $93,85 \%$ & baik sekali \\
\hline Analisis & $89,10 \%$ & $47,99 \%$ & $66,67 \%$ & $66,67 \%$ & $67,61 \%$ & baik \\
\hline Inferensi & $51,28 \%$ & $76,92 \%$ & $94,87 \%$ & $69,23 \%$ & $73,08 \%$ & baik \\
\hline Evaluasi & $72,82 \%$ & $52,31 \%$ & $55,90 \%$ & $75,00 \%$ & $64,01 \%$ & baik \\
\hline Eksplanasi & $84,62 \%$ & $84,62 \%$ & $86,32 \%$ & $100 \%$ & $88,89 \%$ & baik sekali \\
\hline Self Regulation & $48,72 \%$ & $56,41 \%$ & $43,59 \%$ & $33,33 \%$ & $45,51 \%$ & cukup \\
\hline \multicolumn{7}{c}{ Rata-rata Indikator } \\
\hline
\end{tabular}

Berdasarkan Tabel 6, diketahui bahwa rata-rata indikator berpikir kritis memperoleh nilai $72,99 \%$ dengan predikat baik. Hal ini menunjukkan kemampuan berpikir kritis siswa berada pada predikat baik. Hasil yang diperoleh sesuai dengan hasil penelitian Dewa,dkk (2017) yang menyatakan bahwa kemampuan berpikir kritis siswa SMA
Negeri Arjasa pada mata pelajaran fisika bab usaha dan energi tingkat penguasaannya tergolong baik, dengan persentase rata-rata semua indikatornya adalah sebesar $64.91 \%$. Selain itu, Azizah,dkk (2016) juga menyatakan bahwa kemampuan berpikir kritis siswa SMA Negeri 1 Panji termasuk 
kategori baik sekali, dengan persentase $86,9 \%$.

Kemampuan berpikir kritis siswa juga dianalisis berdasarkan hasil pre test dan post test. Berdasarkan hasil uji t (paired samples t-test) menunjukkan hasil analisis nilai $\mathrm{Z}$ sebesar -6.085 dengan signifikansi (sig 2tailed) sebesar 0,000. Nilai signifikansi 0,00 $<0,05$ sehingga dapat disimpulkan ada perbedaan yang signifikan kemampuan berpikir kritis siswa sebelum dan sesudah menggunakan LKS IPA berbasis kearifan lokal kopi. Hal ini sesuai dengan hasil penelitian Sari,dkk (2015) yaitu hasil uji statistik menunjukkan nilai Sig 0,000 $<0,05$ artinya Ho ditolak dan Ha diterima, dengan demikian terdapat perbedaan peningkatan keterampilan berpikir kritis siswa yang signifikan antara yang diterapkan pembelajaran biologi berbasis sains budaya lokal kesenian sintren dan siswa yang tidak diterapkan pembelajaran biologi berbasis sains budaya lokal kesenian sintren.

Hasil uji $\mathrm{N}$-gain menunjukkan ratarata hasil pre test siswa sebesar 24,05 , dan rata-rata hasil post test siswa sebesar 55,63, sehingga skor $N$-gain yang diperoleh sebesar 0,47 tergolong dalam kategori sedang. Kesimpulannya adalah LKS IPA berbasis kearifan lokal kopi pada pokok bahasan usaha dan energi di SMP efektif dalam meningkatkan kemampuan berpikir kritis. Hal ini sesuai dengan hasil penelitian Simbolon,dkk (2015) yaitu siswa yang belajar melalui pembelajaran kontekstual memiliki nilai rata-rata $N$-gain 0,31 , sehingga dapat disimpulkan pembelajaran kontekstual dapat membantu meningkatkan berpikir kritis siswa. Selain itu, Arfianawati, dkk (2016) mengatakan peningkatan kemampuan berpikir kritis pada kelas eksperimen dikategorikan tinggi dengan nilai $\mathrm{N}$-gain 0,77 .

Respon siswa dianalisis menggunakan percentage of agreement untuk menentukan kepraktisan LKS. Adapun data respon siswa yang diperoleh ditunjukkan pada Tabel 7.

Tabel 7. Hasil Respon Siswa

\begin{tabular}{cccc}
\hline No & Aspek & \% & Kategori \\
\hline 1 & Isi & $83,46 \%$ & Sangat Baik \\
\hline 2 & Penyajian & $86,35 \%$ & Sangat Baik \\
\hline 3 & Desain & $84,10 \%$ & Sangat Baik \\
\hline 4 & Bahasa & $90,00 \%$ & Sangat Baik \\
\hline \multicolumn{2}{c}{ Rata-Rata } & $\mathbf{8 5 , 9 8 \%}$ & Sangat Baik \\
\hline
\end{tabular}

Berdasarkan Tabel 7 diketahui bahwa rata-rata nilai percentage of agreement semua aspek sebesar 85,98 \% dengan kategori sangat baik. Sehingga dapat disimpulkan bahwa LKS IPA berbasis kearifan lokal kopi pada pokok bahasan usaha dan energi sangat praktis untuk siswa.

Hasil ini didukung oleh penelitian sebelumnya, diantaranya ialah hasil penelitian oleh Mulyati,dkk (2015) yang menyatakan bahwa, siswa memberikan respon positif terhadap pembelajaran berbasis sains keunggulan lokal penyemaian biji. Selain itu, hasil penelitian lainnya oleh Sholakhudin,dkk (2016) menyatakan bahwa peserta didik mempunyai respon positif terhadap penggunaan Paket Sumber Belajar (PSB) dengan Analisis Foto Kejadian Fisika (AFKF) berbasis kearifan lokal tersebut.

Tahap ketujuh adalah revisi hasil ujicoba. Revisi yang dilakukan berdasarkan hasil penilaian LKS yaitu memperbaiki kegiatan self regulation dan dilakukan penambahan materi pada LKS tentang grafik hubungan ketinggian dengan energi potensial, hukum kekekalan energi mekanik, hubungan usaha dengan energi, serta memberikan contoh perhitungan daya.

\section{SIMPULAN DAN SARAN}

Berdasarkan hasil dan pembahasan yang diuraikan, maka dapat diambil kesimpulan bahwa sebagai berikut: (1) LKS IPA berbasis kearifan lokal kopi pada pokok bahasan usaha dan energi dinyatakan sangat valid atau dapat digunakan tanpa revisi; (2) 
LKS IPA berbasis kearifan lokal kopi pada pokok bahasan usaha dan energi dinyatakan efektif dalam meningkatkan kemampuan berpikir kritis siswa; serta (3) LKS IPA berbasis kearifan lokal kopi pada pokok bahasan usaha dan energi dinyatakan sangat praktis untuk siswa.

Berdasarkan hasil kesimpulan yang diperoleh, maka diajukan beberapa saran sebagai berikut: (1) LKS IPA berbasis kearifan lokal kopi hendaknya digunakan di berbagai sekolah yang juga memiliki kearifan lokal kopi, dan (2) LKS IPA berbasis kearifan lokal kopi hendaknya di perbanyak latihan soalnya agar kemampuan berpikir kritis siswa dapat berkembang lebih baik lagi.

\section{DAFTAR PUSTAKA}

Ain, T.N. 2013. Pemanfaatan Visualisasi Video Percobaan Gravity Current untuk Meningkatkan Pemahaman Konsep Fisika pada Materi Tekanan Hidrostatis. Jurnal Inovasi Pendidikan Fisika. 2(2). 97 - 102.

Akbar, S. 2013. Instrumen Perangkat Pembelajaran. Bandung: ROSDA

Arfianawati, S., Sudarmin, dan Sumarni, W. 2016. Model Pembelajaran Kimia Berbasis Etnosains untuk Meningkatkan Kemampuan Berpikir Kritis Siswa. Jurnal Pengajaran MIPA (JPMIPA). 21(1). 46-51.

Atabaki, A.M.S., Keshtiaray, N., dan Yarmohammadian, M. H. 2015. Scrutiny of Critical ThinkingConcept.Jurnal International Education Studies. 8(3): 93-99.

Azizah, N., Subiki, dan Handayani, R. F. 2016. Penerapan Model Problem Based Instruction terhadap
Kemampuan Berpikir Kritis dan Hasil Belajar Siswa dalam Pembelajaran Fisika di SMA. Jurnal Pembelajaran Fisika. 5(2). 156 - 16.

Dewa, A.D.R.D., Bektiarsoh, S., dan Subiki. Pengaruh Model Pembelajaran Problem Based Instruction disertai Metode Pictorial Riddle terhadap Hasil Belajar dan Kemampuan Berpikir Kritis Siswa pada Mata Pelajaran Fisika di SMA. Jurnal Pembelajaran Fisika. 6(1). hal 48-55.

Emzir. 2013. Metodologi Penelitian Pendidikan:Kuantitatif dan Kualitatif. Jakarta: Rajawali Pers.

Hariri,A.I, Kartimi, dan Mulyani, A. 2016. Penerapan Pembelajaran Berbasis Sains Budaya Lokal Ngaseup pada Konsep Sistem Reproduksi Manusia untuk Meningkatkan Keterampilan Berpikir Kritis Siswa Kelas XI SMAN 1 Maja Jurnal Pendidikan Sains. 5(1): $1-14$.

Isnaningsih dan Bimo, D.S. 2013. Penerapan Lembar Kerja Siswa (LKS) Discovery Berorientasi keterampilan Proses Sains untuk Meningkatkan Hasil Belajar IPA. Jurnal Pendidikan IPA Indonesia (JPII). 2(2): 138.

Lase, N.K., Sipahutar, A., dan Harahap, F. 2016. Pengembangan Lembar Kegiatan Siswa Berbasis Potensi Lokal pada Mata Pelajaran Biologi SMA Kelas XII. Jurnal Pendidikan Biologi. 5 (2) : 99-107.

Martawijaya, M A. 2015. Karakter Peserta Didik dan Hubungannya dengan Keterampilan Berpikir Kritis dalam Pembelajaran Fisika Siswa SMP. 
Journal of Educational Science and Technology . 1(2): $1-7$.

Mulyati, D.S., Kartimi, dan Mulyani, A. 2015. Penerapan Pembelajaran Berbasis Sains Keunggulan Lokal Penyemaian Biji Mangga di Salagedang terhadap Keterampilan Berpikir Kritis Siswa pada Materi Ekosistem Kelas X SMA Negeri 1 Sukahaji Kabupaten Majalengka. Jurnal Scientiae Educatia. 5(1):1-11.

Permatasari, A.O dan Ismono. 2017. Pengembangan Lembar Kerja Siswa (LKS) Berorientasi Kooperatif Tipe Think Pair Share untuk Melatihkan Keterampilan Berpikir Kritis pada Materi Termokimia Kelas XI MIA 1 SMAN 1 Bangkalan. UNESA Journal of Chemistry Education. 6(1): 24-29.

Qolbi, F., Kartimi, dan Roviati, E. 2016. Penerapan Pembelajaran Berbasis Sains Budaya Lokal Ngarot untuk Meningkatkan Keterampilan Berpikir Kritis Siswa pada Konsep Plantae (Studi Eksperimen Kelas X Di SMA N 1 LOHBENER). Jurnal Sains dan Pendidikan Sains. 5(2): 105-121.

Riduwan. 2015. Skala Pengukuran Variabel Penelitian. Bandung: Remaja Rosdakarya.

Sari, J.R., Kartimi, dan Fitriah, E. 2015. Penerapan Pembelajaran Biologi Berbasis Sains Budaya Lokal
Kesenian Sintren pada Konsep Spermatophyta untuk Meningkat-kan Keterampilan Berpikir Kritis Siswa SMAN 1 Ciwaringin. Jurnal Scientiae Educatia. 5(1): 1-12.

Sholakhudin, M.N., Sutarto, dan Subiki. 2016. Paket Sumber Belajar (PSB) dengan Analisis Foto Kejadian Fisika (AFKF) Berbasis Kearifan Lokal pada Pembelajaran Fisika di SMK (Kajian Pengembangan pada Pokok Bahasan Fluida untuk SMK Jurusan Perikanan dan Kelautan). Jurnal Pembelajaran Fisika. 5(3): 253- 260.

Simbolon, E.R., dan Tapilouw, F. S. 2015. Pengaruh Pembelajaran Berbasis Masalah dan Pembelajaran Kontekstual terhadap Berpikir Kritis Siswa SMP. Jurnal Edusains . 7 (1): 97-104.

Sochibin, A., Dwijananti, P., dan Marwoto, P. 2009. Penerapan Model Pembelajaran Inkuiri Terpimpin untuk Peningkatan Pemahaman dan Keterampilan Berpikir Kritis Siswa. Jurnal Pendidikan Fisika Indonesia. 5(2): 96-101.

Wahyuni, S. 2015. Developing Science Learning Instruments Based on Local Wisdom to Improve Students' Critical Thinking Skills. Jurnal Pendidikan Fisika Indonesia. 11(2):156-161. 